\title{
Human Leukocyte Antigen System: Population and Immunogenetic Analysis of Three Ecuadorian Populations
}

\author{
F. De Angelis ${ }^{1}$, A. Battistini ${ }^{1}$, A. Garzoli ${ }^{1}$, A. Iorio', G.F. De Stefano' \\ ${ }^{1}$ Department of Biology, University of Rome Tor Vergata, Via della Ricerca Scientifica 1, 00133, Rome, Italy. \\ E-mail: flavio.de.angelis@uniroma2.it
}

KEYWORDS: HLA, Ecuador, human populations.

\section{Introduction}

In recent decades, new contributions in population genetics and molecular anthropology allowed to better define the extent of genetic variability in humans and the processes that underlie it (Cavalli-Sforza and Feldman, 2003).Today, human DNA is known to be the main object of population studies, yet the choice of populations, markers, genotyping procedures and statistical methods, play a key role for these analysis (Cavalli-Sforza, 2005).

The preferred regions in population studies are those that exhibit high degree of polymorphism, have significantly different frequency distribution in different groups and carry signature haplotypes in different populations (CavalliSforza, 2005). Several polymorphic regions of human genome have been used in recent years to infer population relationships, and among them our attention is focused on Human Leukocyte Antigen (HLA) genomic area.

The HLA complex is located in three main regions of chromosome 6, that include the class I and class III (telomeric) and class II (centromeric) loci (Middleton, 1999). Among class II loci, our interest is focused on HLA-DQ, that like every HLA class II encodes proteins on specific antigen-presenting cells. These molecules are heterodimers encoded by DQA1 and DQB1 genes. HLA genetic variation has come under recent inquiry because of its extreme polymorphic nature (Jin and Wang, 2003). The high rate of polymorphism of HLA loci offers the possibility to infer human population relationship: several reasons suggest to believe that HLA class II loci are comparable with $\mathrm{mtDNA}$ and $\mathrm{Y}$ chromosome markers in phylogenetic assessment (Agrawal et al., 2007; Arnaiz Villena et al., 2004). They are both vastly polymorphic and highly linked loci that results into unique linkage disequilibria pattern, signature alleles and haplotype segregation among different populations. Notwithstanding the notion that selection during epidemics or long periods of exposure to infectious diseases might play a major role in development of allelic diversity of human populations is not new (Herris and Meyer, 2006). Clearly, an analysis of the human genome with respect to susceptibility to infections has already provided important new insights into the mechanisms of human diversity. Thus the aim is to test the power of HLA in both the aspects of this very interesting genetic complex in three Ecuadorian populations.

The actual cultural diversity of the Ecuadorian Country is represented by 17 main ethnic groups and comes from several processes of adaptation to a wide range of habitat, immigration, the Spanish conquest in the sixteenth century and to the arrive and the mixture of Africans (De la Torre and Balslev, 2008). In this multiethnic country three populations live in the north-western area: two of them live along the Cayapas river in the province of Esmeraldas, while the third is settled in the southward canton of Santo Domingo de los Colorados. The populations living in Esmeraldas are scattered in a typical tropical rainforest environment and are a group of Amerindian, the Cayapa Indians, and people of African ancestry (De Stefano et al., 1994; Polimanti et al., 2011; De Angelis et al., 2012). Cayapa Indian origins seem to derive by mixed Andean and northern Sout-American people (Barriga Lopez, 1987; Rickards et al., 1999). The first Africans reached the coast of Esmeraldas Province about in the middle of $16^{\text {th }}$ century: they are reported as a little group who first settled on the coast near Esmeraldas town (De Stefano, 1994). Although it is not clear when they first moved inland from the coast, the Africans were reported to have been settles along Cayapas River at the beginning of the $18^{\text {th }}$ century (Martinez-Labarga et al., 1999). Cayapas and Afroecuadorians live very close to each other, yet there is very little intermarriage between them, and indeed this seems to have been till now highly discouraged (Rickards et al., 1999). The third population is settled in Santo Domingo de los Colorados: they are the Tsachilas Indians. The Tsachilas are represented by approximately 2500 people clustered in eight communities. Hunting, fishing and gathering were originally the main activities, however, no longer practiced because of the lack of suitable land for these practices. They are called also Colorados because men manage their hair as a cap painted with achiote (Bixa orellana) and oil.The present research aimed to analyze the HLA-DQ profile of these population to ascertain their genetic relationships with neighbor human groups. These data were compared with other Amerindian groups and worldwide populations.

\section{Materials and Methods}

Recruiting was carried out in Rio Cayapas area and Chiguilpe community of Tsachilas by one of us (GFDS). 
DNA was extracted from whole-blood samples (Miller et al., 1988) of 110 unrelated Cayapas, 101 Afroecuadorians and $52 \mathrm{Tsachilas.} \mathrm{Individuals} \mathrm{were} \mathrm{of} \mathrm{both} \mathrm{sexes,} \mathrm{between}$ 7 and 66 years of age, who gave their informed consent. HLA-DQA1 and HLA-DQB1 loci were high-resolution typed by direct sequencing of exons 2 and 3 .

The methodology for amplifications and sequencing are listed in previous paper (De Angelis et al., 2012).All class II alleles included in the present study are four-digit resolution data. Overall distributions of HLA-DQ alleles were determined by the direct counting method. To infer relationships between different populations by HLA class II loci, a database of $\mathbf{3 0}$ geographically and ethnically different populations has been compiled. Similarity reconstruction was carried out by Nei's distances (Nei, 1987). Genetics distances were used to draw up a multivariate display of the population similarity by Multidimensional Scaling (MDS), performed by PAST software (Hammer et al., 2001).

\section{Results}

The Figure 1 shows the HLA-DQA1 distribution of the data sets. This points out an expected allele diversity among Ecuadorian people, not only between Amerindians and Afroecuadorians, but also between Amerindians. In fact if the leading frequency in Afroecuadorians is $32 \%$ for *0102, the most frequent DQA1 allele in Cayapas is *0301 $(29 \%)$ while in Tsachilas is *0401 (28\%). Although the slight differences among populations, it is interesting to note the significant amount of DQA $1 * 0401$ in every populations.

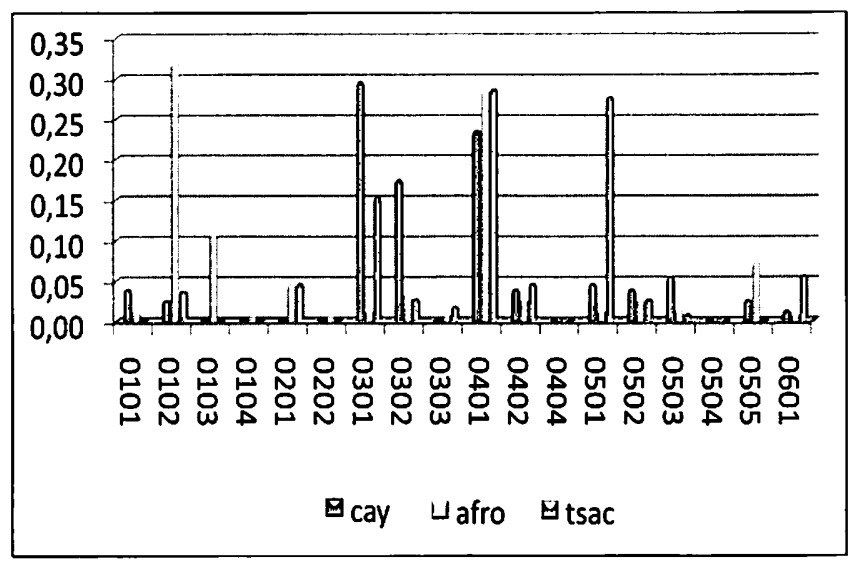

Fig. 1. HLA-DQA1 allele distributions in the three Ecuadorian samples.

Also for HLA-DQB1 there are substantial differences among Ecuadorian samples (Fig. 2).

The leading allele in Afroecuadorians is the *0301 (26\%), while in Cayapas is the $0302(31 \%)$ like in the Tsachilas (23\%).The calculation of Nei's genetic distance allows to identify the relationships among populations: to do that, a dataset of 30 populations has been compiled from $\mathrm{www}$. allelefrequencies.net, as reported in Tab. 1.

The MDS made by Nei's distance of HLA-DQA1 gene highlights a clear separation among ethno-geografic cluster: in fact it is possible to distinguish an African cluster, in

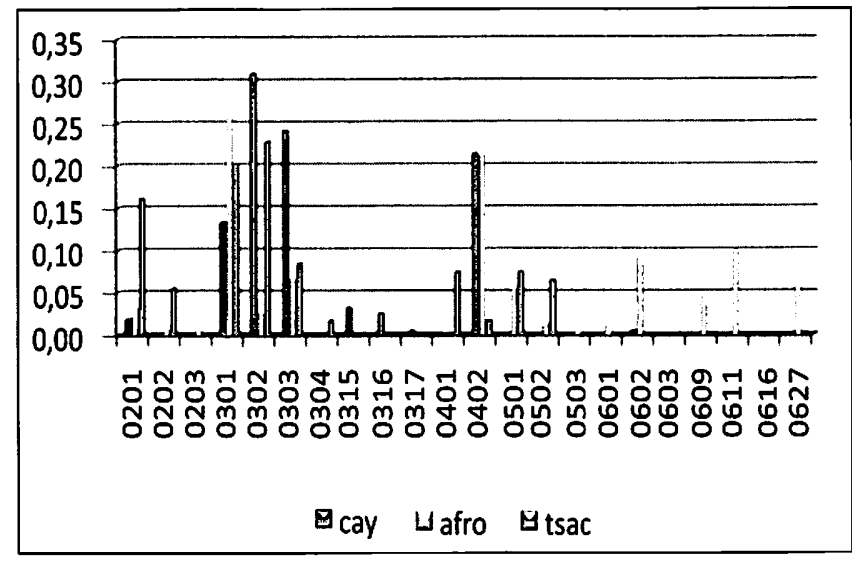

Fig. 2. HLA-DQB1 allele distributions in the three Ecuadorian samples.

\begin{tabular}{|l|l|l|l|}
\hline \multicolumn{1}{|c|}{ Code } & \multicolumn{1}{c|}{ Country } & \multicolumn{1}{c|}{ Code } & \multicolumn{1}{c|}{ Country } \\
\hline ArgeBA & Argenitna & Jamaica & Jamaica \\
\hline ArgMatWic0 & Argenitna & Japan & Japan \\
\hline ArgChirigu & Argentina & Kenya & Kenya \\
\hline ArgGrChaET & Argentina & MexMayp2 & Mexico \\
\hline AusAboKim0 & Australia & MexMayp2 & Mexico \\
\hline Bamileke & Cameroon & MexSenSeri & Mexico \\
\hline ChiSanpop2 & China & MexMazate & Mexico \\
\hline ChinaBeiXi & China & MexGuaMes & Mexico \\
\hline ColAmaCore & Colombia & MexjalMeet & Mexico \\
\hline ColAmaNuca & Colombia & MexHigMes & Mexico \\
\hline ColArSeNe & Colombia & PerùQuechu & Peru \\
\hline CongoBantu & Congo & SouthKorea & Sout Korea \\
\hline Oromo & Ethiopia & Taiwan & Taiwan \\
\hline Amhara & Ethiopia & Uganda & Uganda \\
\hline GuaMesMex & Guatemala & VenSierra & Venezuela \\
\hline
\end{tabular}

Tab. I. Compared populations from www.allelefrequencies.net

white, an Asian cluster, in black, and an American cluster, in grey. The Cayapas and Tsachilas lie in the American cluster, while the Afroecuadorians of Esmeraldas are placed in the middle between Americans and African populations: this confirms the mixed nature of the sample.

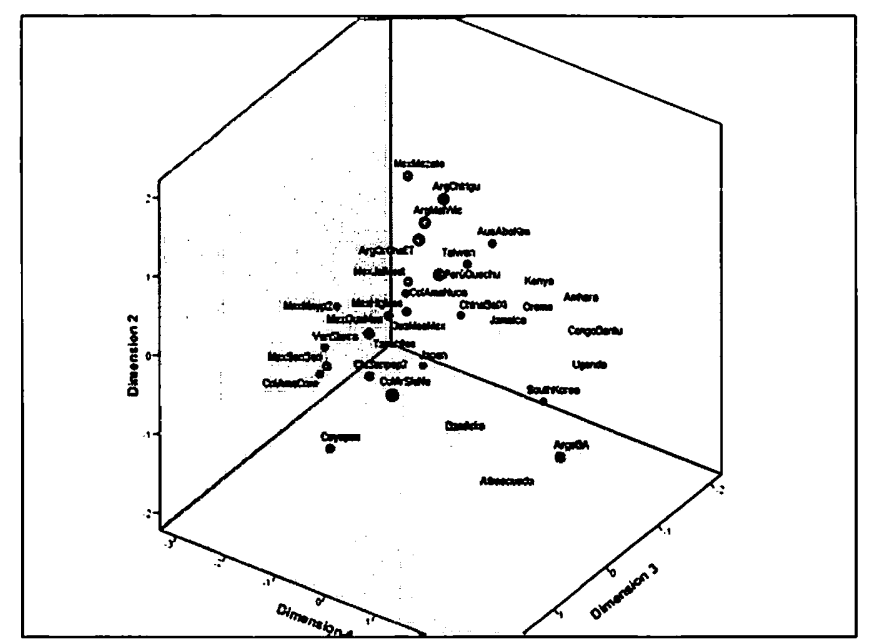

Fig. 3. MDS made by Nei's Distance on HLA-DQA1 allele frequencies. 
The figure 4 shows a more nuanced scenario for HLADQB1, although a general geographic constrain seems to be respected.

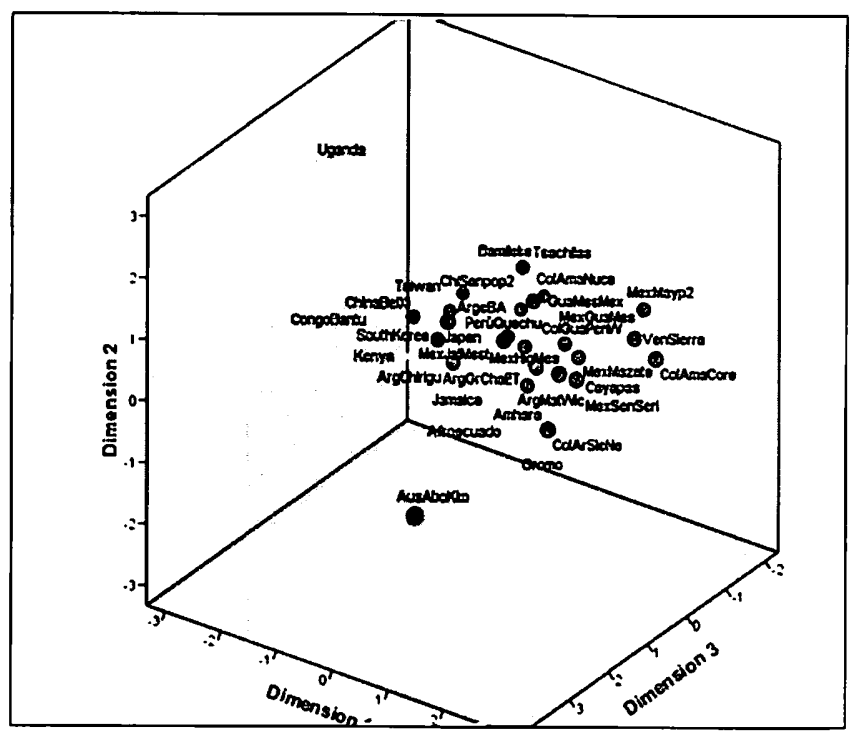

Fig. 4. MDS made by Nei's Distance on HLA-DQB1 allele frequencies.

This could be due to the functional constrain of the peptide encoded by HLA-DQB1. In fact it is the essential section of HLA-DQ heterodimer to the housing of the antigenic peptide within the binding cleft of the HLA molecule. Thus it is guessed how this locus might be subjected to wider selective force resulting in loss of quality in the discriminatory inference of the population relationships.

A more clear picture seems to be detected by the MDS made by both loci. In fact if HLA-DQA1 and HLA-DQB1 were considered, an unambiguous picture is depicted by MDS: moreover a fourth cluster appears, that is the group of south-american populations.

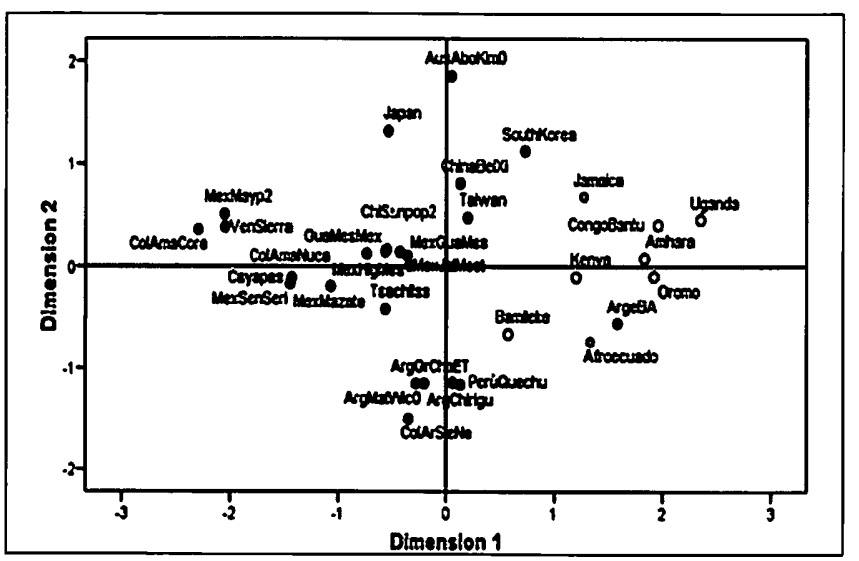

Fig. 5. MDS made by Nei's Distance on HLA-DQA1 and HLA-DQB1 allele frequencies.

The reported results highlight how this genetic system might be useful in determine the genetic relationships among populations. Notwithstanding this property, the HLA is a genetic complex involved in the response to several endogenous and exogenous factors responsible for diseases.A case report of the importance of this genetic complex has been recently expressed related to onchocerciasis (De Angelis et al., 2012). In this research two out three Ecuadorian populations have been analyzed as a model to investigate the importance of HLA against infection by onchocerca volvulus: the Cayapas and the Afroecuadorians. This study exploited the unique opportunity to test two populations of different ethnic backgrounds collocated in a single environment, which may be very meaningful for detecting immunogenetic strength in response to onchocerciasis. In our paper we demonstrate that the very impressive frequence of HLA-DQA $1 * 0401$ might be related to a putative genetic protection against the onchocerca infection (Figure 6 ) as confirmed also by Mantel-Henszel OR $=0.2\left(p_{\text {corrected }}<0.0001\right)$. The same allele is significantly present in Tsachilas healthy people, whose biological samples have been included in the population analysis.
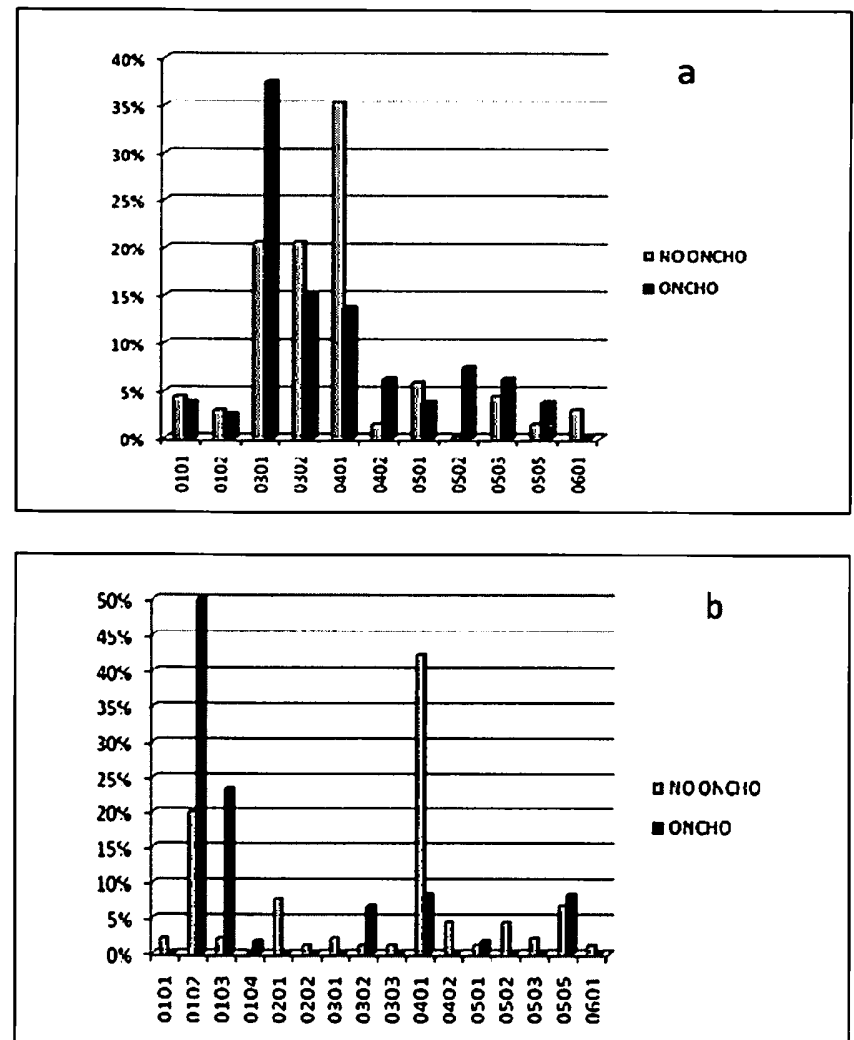

Fig. 6.HLA-DQA1 allele frequencies in Cayapas (a) and Afroecuadorians (b) subdivided by clinical status related to onchocerciasis.

It is interesting to note the high frequency of HLADQA1*0401 in the sample that might be an evidence of a putative genetic protection against helminth infections, in particular onchocerciasis, although no individual data are available about the presence/absence of disease in the Tsachilas (De Angelis et al., 2012). The establishment of a new increasing focus of onchocerciasis was suspected in the Tsachilas because of the immigration of Cayapas from hyperendemic onchocerciasis focus over the last 20 years (Cooper et al., 2001) and the presence of the vector species Simulium exiguum (Charalambous et al., 1997). Thus the random sampling of apparently healthy people might 
be inclusive of protected people against onchocerciasis carrying the protective allele DQA $1 * 0401$.

\section{References}

Agrawal S., Khan F., Bharadwaj U. 2007. Human genetic variation studies and HLA class II loci. Int. J. Immunogenet, 34: 247-252.

Arnaiz-Villena A., Siles N.., Moscoso J., Zamora J., Serrano-Vela J.I., Gomez-Casado E., Castro MJ., Martinez-Laso J. 2005, Origin of Aymaras from Bolivia and their relationship with other Amerindians according to HLA genes. Tissue Antigens, 65: 379 390.

Barriga Lopez F., 1987. Cayapas o Chachis,Vol 4, Graficas Duque. Instituto Ecuatoriano de Credito Educativo y Becas, Quito, Ecuador.

Cavalli-Sforza L.L., Feldman M.W. 2003.The Application of Molecular Genetic Approaches to the Study of Human Evolution. Nature Genetics, Supplement, 33: 266-275.

Cavalli-Sforza L.L., 2005.The Human Genome Diversity Project: past, present and future. Nat. Rev. Genet., 6: 333-340.

Charalambous M., Shelley A.J., Arzube M. 1997. The potential for dispersal of onchocerciasis in Ecuador in relation to the distribution of the vector Simulium exiguum (Diptera:Simuliidae). Mem. Inst. Oswaldo Cruz., 92: 153-156.

Cooper P... Mancero T., Espinel M., Sandoval C., Lovato R., Guderian R.H., Nutman T.B. 2001. Early human infection with Onchocerca volvulus is associated with an enhanced parasitespecific cellular immune response. J. Infect. Dis., 183: 1662 1668.

De Angelis F., Garzoli A., Battistini A., lorio A., De Stefano G. F. 2012. Genetic Response to an Environmental Pathogenic Agent: HLA DQ and Onchocerciasis in Northwestern Ecuador. Tissue Antigens, 79: 123-129.
De la Torre L., Balslev H. 2008. Introducción. In: De la Torre L. Navarrete P., Muriel M., Macía M., Balslev H. (eds.) Enciclopedia de las Plantas Útiles del Ecuador. PUCE, Quito \& Universidad de Aarhus, Aarhus: 1-3.

De Stefano G.F. 1994. Biodiversity and selection in man: an example of biodiversity maintenance by non- adaptive factors. Biol. Internation. Spec. Issue, 32:63-71.

Hammer Ø., Harper D.A.T., Ryan P.D. 2001. PAST: Paleontological Statistics Software Package for Education and Data Analysis. Palaeontologia Electronica, 4: 9.

Harris E.E., Meyer D. 2006. The molecular signature of selection underlying human adaptations. Am.J. Phys.Anthropol., 43: 89-130.

Jin P.,Wang E. 2003. Polymorphism in clinical immunology - From HLA typing to immunogenetic profiling. J. Transl Med., 18: 1-8.

Martinez Labarga C., Rickards O., Scacchi R., Corbo R.M., Biondi G., Pena J.A., Varas DeViera C., Guevara A.E.B., Mesa Santurino M.S., De Stefano G.F. 1999. Genetic population structure of two african-ecuadorian communities of Esmeraldas. Am. J. Phys. Anthropol., 109: 159-174.

Miller S.A., Dykes D.D., Polesky H.F. 1988.A simple salting out procedure for extracting DNA from nucleated cells. Nucleic Acids Res., 16: 1215.

Middleton D. 1999. History of DNA typing for the human MHC. Reviews in Immunogenetics, 1: 135-156.

Nei M. 1987. Molecular Evolutionary Genetics. University of Columbia Press, New York, USA.

Polimanti R., Piacentini S., De Angelis F., De Stefano G.F., Fuciarelli M. 2011. Human GST loci as markers of evolutionary forces: GSTO1*E155del and GSTO1*E208K polymorphisms may be under natural selection induced by environmental arsenic. Dis. Markers., 31: 231-239.

Rickards O., Martinez-Lambarga C., Lum J.K., De Stefano G.F., Cann R.L. 1999. mtDNA history of the Cayapa Amerinds of Ecuador: detection of additional founding lineages for Native American populations. Am. J. Hum. Genet., 65: 519-530. 